\title{
Factors of sexual quality of life in gynaecological cancers: a systematic literature review
}

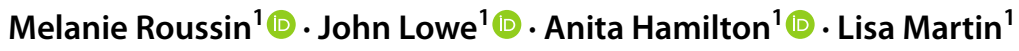

Received: 3 November 2020 / Accepted: 27 March 2021 / Published online: 13 April 2021

(c) The Author(s) 2021

\begin{abstract}
Background The impact of cancer diagnosis and treatment on sexual quality of life (SQoL) is a well-established survivorship issue for gynaecological cancer survivors (GCS), yet little is known on how to intervene.

Purpose The aim of this systematic review was to identify the factors explaining the variability in SQoL for GCS.

Methods We used the Preferred Reporting Items for Systematic Reviews and Meta-Analyses (PRISMA) framework and the software Covidence. Electronic databases Scopus, Web of Science, PUBMED and CINAHL were searched for original research on GCS published between 2002 and 2018. We performed a two-stage screening process against selection criteria and quality assessment of individual studies. The Salutogenic Theory and the PRECEDE-PROCEED model were used as theoretical frameworks to identify and categorise factors.

Results The initial search yielded 3,505 articles resulting in a total of 46 studies used to examine the association between factors of SQoL and gynaecological cancers. Our findings suggested that SQoL varies across subgroups based on age, menopausal status, relationship status, and treatment modality. Protective factors included clinicians' knowledge and confidence, preventive medical approach, risk and needs assessment, patient-clinician communication, relationship quality, psychosocial support, symptom management, accessibility of psychosexual care, and self-efficacy in the rediscovery of sexuality.

Conclusion Despite the high incidence and long-term impact of sexual health issues on quality of life, supportive care needs are not being met. A better understanding of the evidence base around the factors of SQoL can help health professionals take steps to protect and improve SQoL in GCS.
\end{abstract}

Keywords Gynaecological cancer $\cdot$ Female cancer survivors $\cdot$ Sexual quality of life $\cdot$ Healthy sexuality $\cdot$ Factors . Systematic review

\section{Introduction}

\section{SQoL as a key survivorship issue for GCS}

Melanie Roussin

melanie.roussin@research.usc.edu.au

John Lowe

Jlowe@usc.edu.au

Anita Hamilton

ahamilt1@usc.edu.au

Lisa Martin

Lisa.Martin@usc.edu.au

1 School of Health and Behavioural Sciences, University of the Sunshine Coast, 90 Sippy Downs Drive,

Sunshine Coast, QLD 4556, Australia
Although survival rates for women diagnosed with gynaecological cancers are improving, the quality of life (QoL) for those women and their families often suffer as a result [1-3]. The World Health Organization (WHO) and the literature have characterised sexuality as a human right and a key component of QoL [2, 4-6]. In 2012, an estimated three million women worldwide were living with gynaecological cancers, with more than half experiencing sexual difficulties $[2,7]$. High rates of sexual dysfunction, sexual inactivity and sexual morbidity in this population have been shown to greatly impact QoL $[3,5,7,8]$. The term "sexual quality of life" (SQoL) emphasises this link between sexuality and QoL [7-11]. 
Despite sexuality being recognised as a key survivorship issue for gynaecological cancer survivors (GCS) [12, 13], little is known on how best to support SQoL in this population [8, 14]. This is an important public health issue considering that cancer treatment can extend life expectancy by 25-30 years [15]. Furthermore, there is growing evidence for the need to integrate sexuality as part of routine care in gynaecological cancer recovery given current unmet needs [3, 16]. Consequently, further investigation was warranted to understand the factors that are amenable to public health action to protect and improve SQoL.

\section{Defining SQoL_-beyond sexual dysfunction}

Beckjord and Campas [11] defined SQoL for female cancer survivors as a broad concept covering sexual attractiveness, interest, participation and function. Interestingly, McCallum et al. [14] found that the meaning of healthy sexuality for GCS includes concepts of emotional intimacy, body image, sexual self-schema, and sexual response. They also discovered that sexuality is shaped by the interplay of physical, psychologi$\mathrm{cal}$, and interpersonal experiences. Similarly, WHO recognises sexuality as being "influenced by the interaction of biological, psychological, social, economic, political, cultural, legal, historical, religious and spiritual factors." [6] As such, WHO defines sexual health as "a state of physical, emotional, mental, and social well-being in relation to sexuality; it is not merely the absence of disease, dysfunction or infirmity" [6].

The literature on sexuality and gynaecological cancers has predominantly focused on sexual dysfunction and sexual inactivity - at the expense of a more salutogenic approach to SQoL $[2,12,17,18]$. Contrary to the disease orientation, salutogenesis [19] promotes the creation of health. To maximise health outcomes, it is imperative to go beyond common complaints of sexual dysfunction or lack of desire [2] and acknowledge the complex interplay of individual, social and environmental factors. Consequently, this review used the Salutogenic Theory [19] and the WHO definition of sexual health to explore how to move GCS towards greater SQoL by understanding the factors that relate to all aspects of the person-rather than merely sexual dysfunction. The aim of this systematic review was to identify the risk and protective factors that have been studied as explanations of variability in the SQoL of GCS. Our research question was: what are the risk and protective factors of SQoL in GCS?

\section{Methods}

\section{Search strategy}

We used the Preferred Reporting Items for Systematic Reviews and Meta-Analyses (PRISMA) framework and the software Covidence in this systematic review [20, 21]. The search for eligible studies was conducted in four electronic databases, Scopus, Web of Science, PUBMED, and CINAHL for articles published in English between 2002 and 2018. The search strategy was developed with input from a health librarian with expertise in systematic review searching. Search terms, such as "sexual quality of life", "sexual health", and "sexual wellbeing", were combined with terms such as "factor", "predictor", and "cause" for each gynaecological cancer. Two reviewers performed a two-stage screening process (abstract and title, then full text) against selection criteria and a third investigator solved any discrepancy. All voting was blinded, meaning that contributors were unable to see each other's votes until they casted their own.

\section{Inclusion and exclusion criteria}

The inclusion criteria included peer-reviewed studies reporting the factors of SQoL for adult women diagnosed with gynaecological cancer. Gynaecological cancers were defined as those affecting a woman's reproductive system: ovarian, uterine, cervical, vulvar, and vaginal cancers [22, 23]. In addition, cancers of the placenta and fallopian tubes were included. Studies of women for pre-cancerous or other health conditions were excluded. Studies addressing both gynaecological and non-gynaecological cancers (e.g., studies of ovarian and breast cancers) were included if gynaecological cancer data were reported separately. No study design was imposed on the original search. We included randomised control trials, qualitative studies, cohort studies, and case-control studies published in English. Studies were excluded if they contained data from other sources than original full-text publications (i.e., reviews, meta-analyses), but reference lists were scrutinised for completeness. Finally, studies were excluded if they did not report at least one factor explaining the association between SQoL and one or more of the gynaecological cancers studied.

\section{Quality assessment and data extraction}

Two investigators, one of whom was not involved in article screening and selection, completed quality assessment and preliminary data extraction of individual studies independently. The process was blinded and Critical Appraisal Skills Programme (CASP) checklists [24] were used as standardised tools to critically appraise articles. To be retained for inclusion, studies had to clearly answer the research question and reach a minimum quality score of $50 \%$. Conflicts were resolved by consensus. Studies' general characteristics (author, year of publication, aim, number of participants, country, design, outcome measures, tools, and theoretical frameworks), as well as the clinical characteristics of the patients or survivors (age, FIGO stage, cancer site, etc.) were 
extracted and tabulated along with factors and recommendations to perform a thematic analysis. All data in this review were obtained from previously published and publicly available studies.

\section{Data analysis}

The Salutogenic Theory and the PRECEDE-PROCEED planning model $[25,26]$ were used as theoretical frameworks to identify and categorise factors. Hence, classification of protective factors was performed using predisposing, enabling and reinforcing factors. Predisposing factors are involved at the cognitive level such as knowledge, attitudes, and self-efficacy of GCS in SQoL. Enabling factors are the conditions that help SQoL to occur (e.g., availability of resources, funding or guidelines). Reinforcing factors are those helping to support SQoL in a community and thus involving partners, peers, health providers, etc.

This study revealed the risk and protective factors of SQoL. By risk factors, we refer to the factors that may increase the likelihood of an impaired SQoL in GCS. For example, single irradiated women may be more at risk of an impaired SQoL. In comparison, protective factors may decrease the likelihood of an impaired SQoL. For instance, patient-clinician communication may help protect and improve SQoL.

\section{Results}

A total of 3505 articles were identified by our search strategy. Figure 1 shows the PRISMA diagram for the different phases of the systematic review process, which resulted in the inclusion of 46 studies. Table 1 (Appendix A) presents the characteristics of included studies.

\section{Risk factors of SQoL}

Our findings suggest that the SQoL of GCS varies across subgroups based on age, menopausal status, relationship status, and treatment modality (Table 2). To a lesser extent, variations in SQoL have been attributed to cancer site [27], tumour stage [28], BMI [29], education [30-33], and unemployment [30]. Due to space constraints, we will report only on the factors with the strongest evidence.

\section{Age and menopausal status}

Age seems to be a significant consideration when assessing the support needs of GCS. Out of 46 studies, 12 reported an association between age and SQoL [14, 27, 29-31, 33-39].

GCS aged over 50 may be more likely to suffer from orgasmic disorders and less likely to discuss sexual concerns

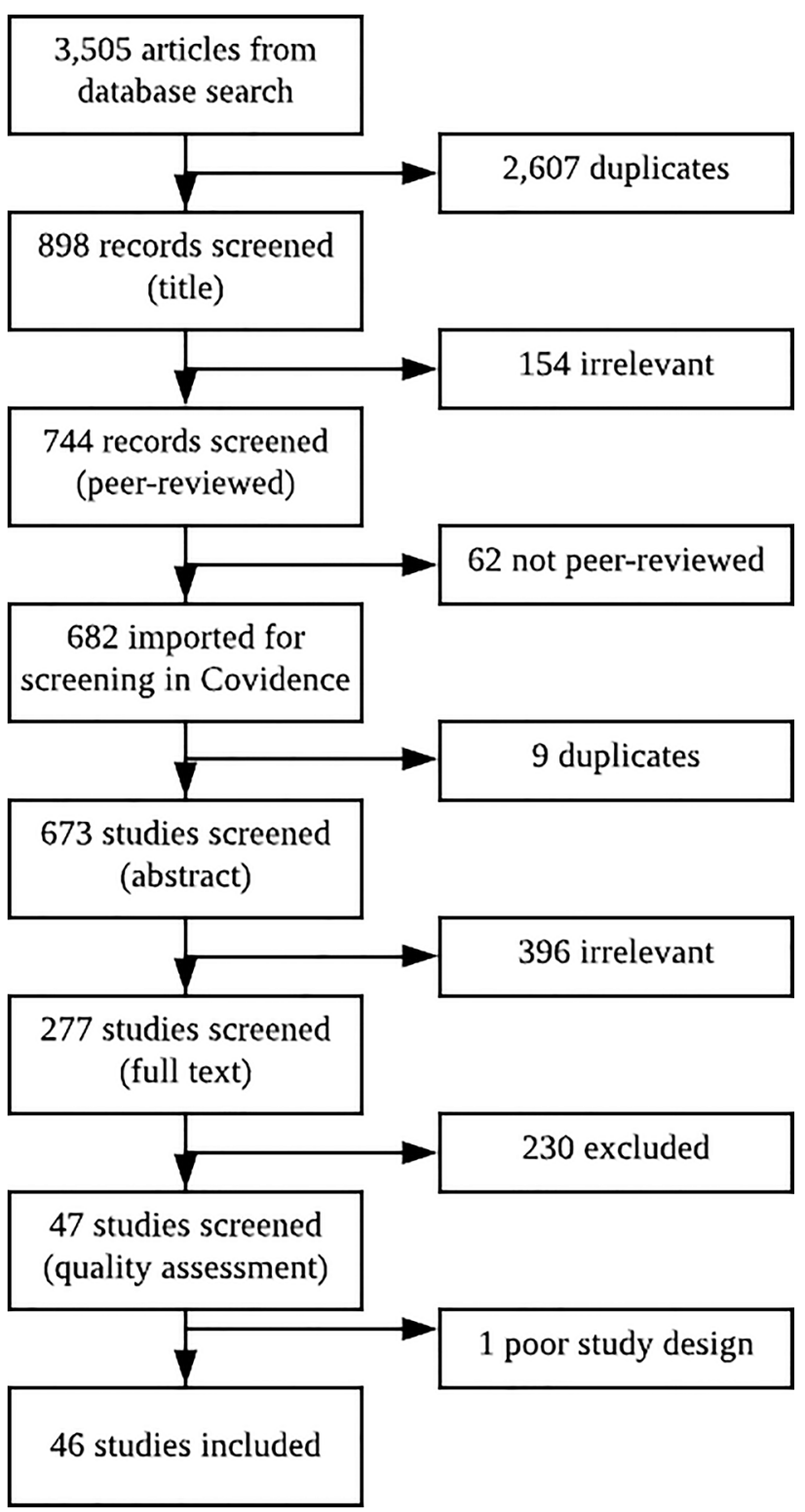

Fig. 1 PRISMA diagram for the systematic review

due to shyness and stigma [14]. Whereas, their younger counterparts have reported feelings of aloneness [27], relationship dissatisfaction [35], distress about long-term sexual problems [39], and concerns about how they feel cancer changed their body [30, 39].

Overall, young age was associated with worst adaptation on a range of SQoL measures ranging from the number of sexual problems to the severity of psychosexual distress [39]. In fact, women aged less than 55 years requested help to deal with sexual and psychological complications [34, 39], but stated practical considerations and emotional avoidance as barriers to access services [14]. Although sexual problems, such as the lack of sexual desire, were discussed among both groups [14, 29-31, 33, 35, 38]. Corrêa et al. [31], Segal et al. 


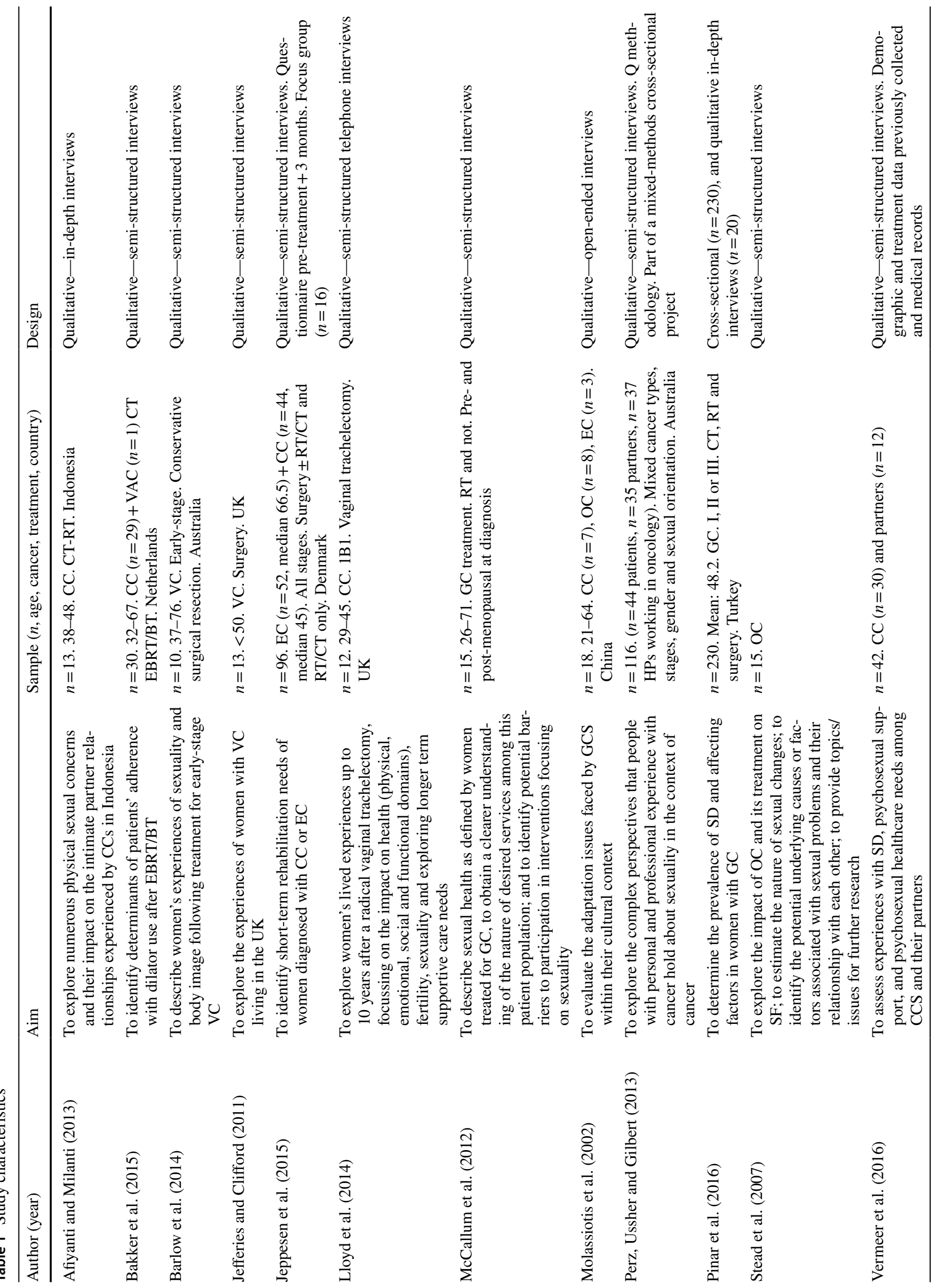




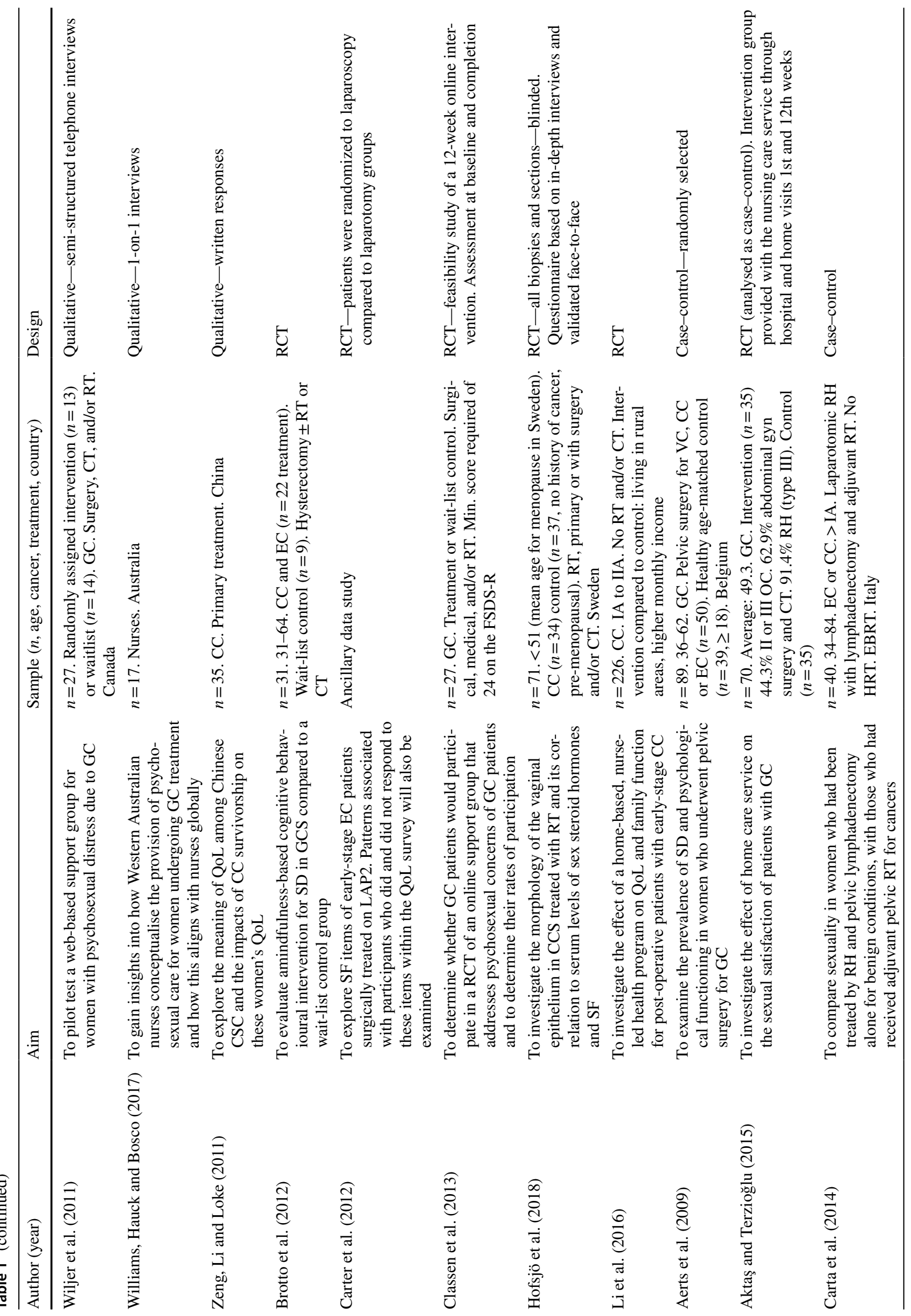




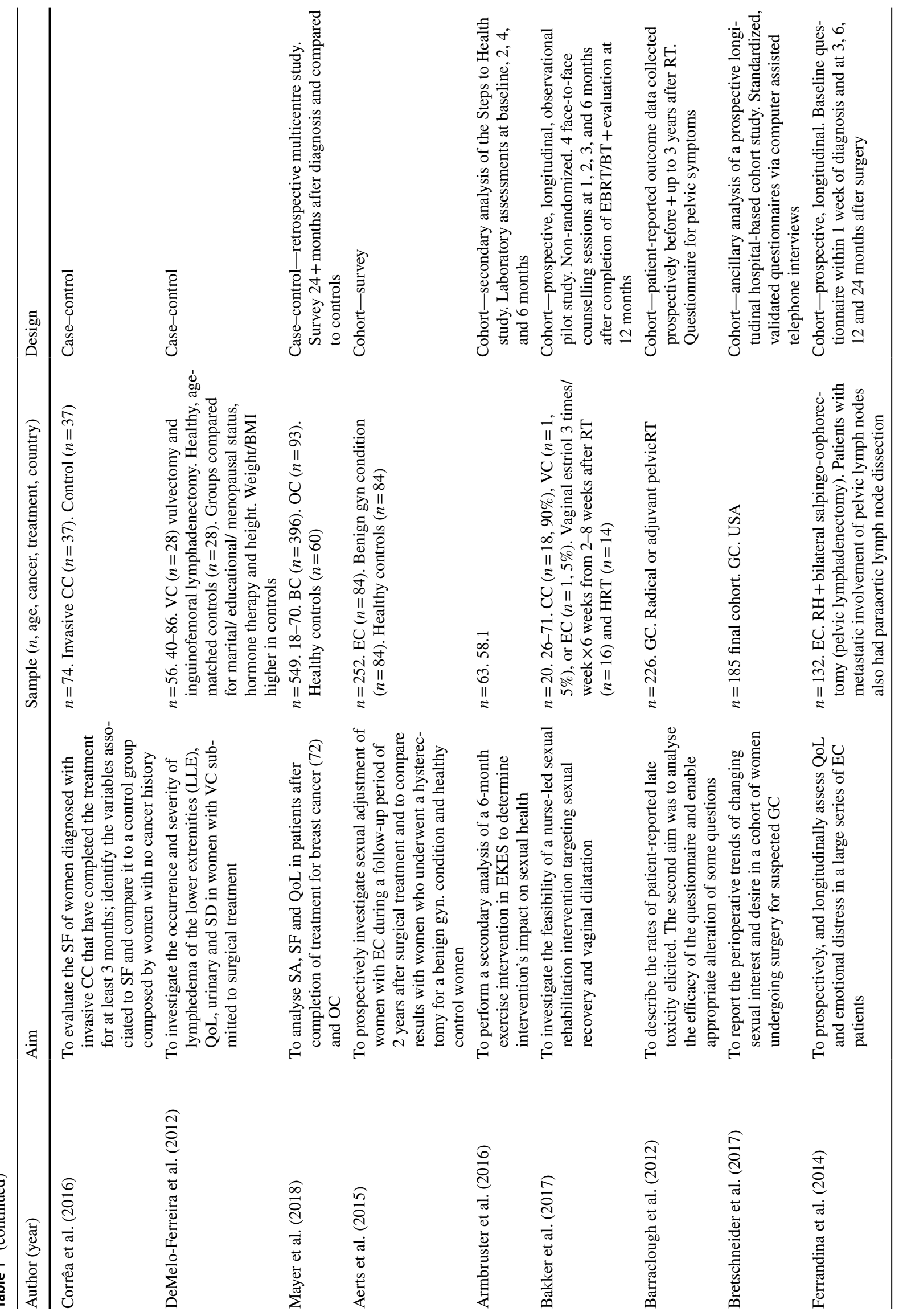




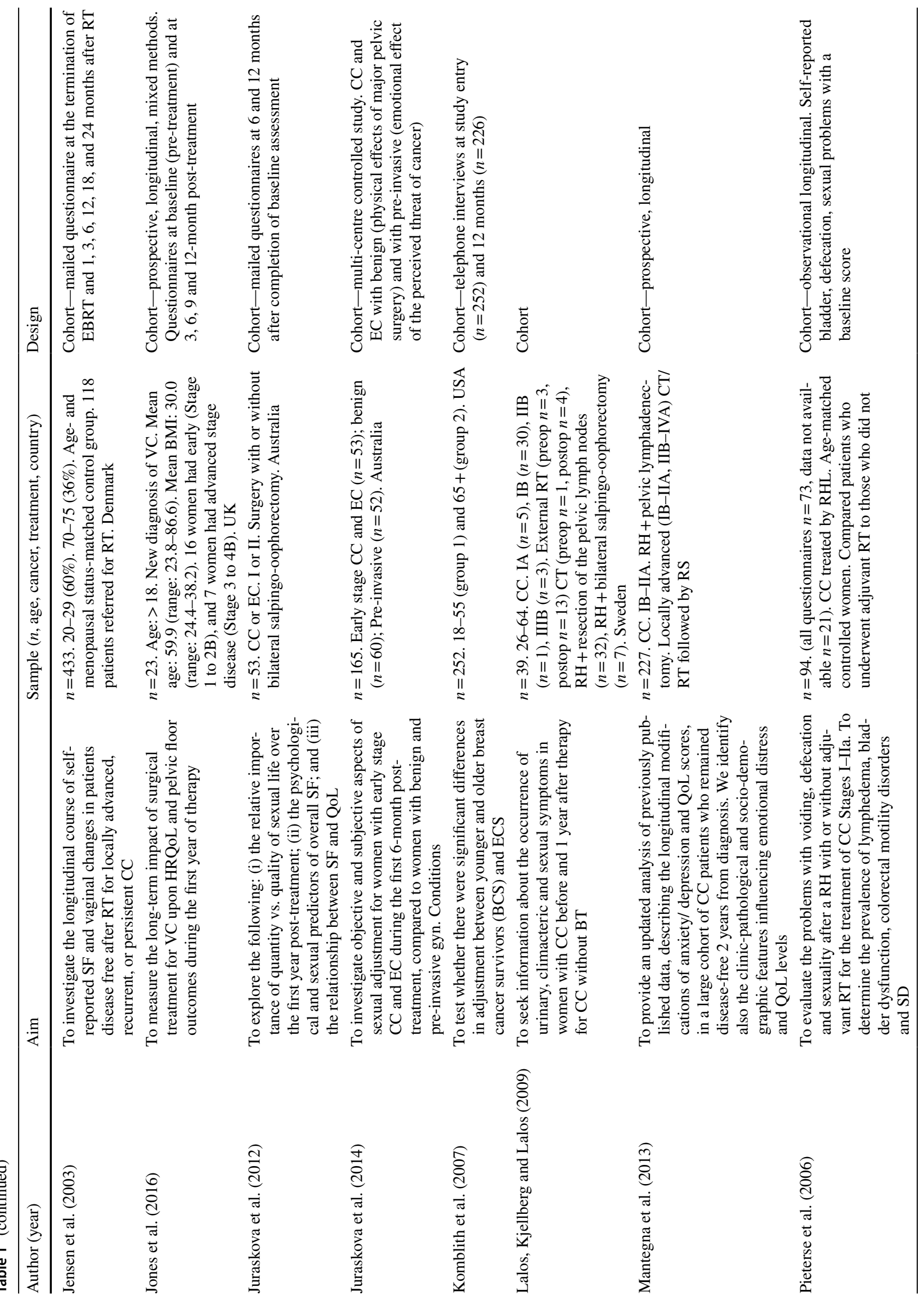




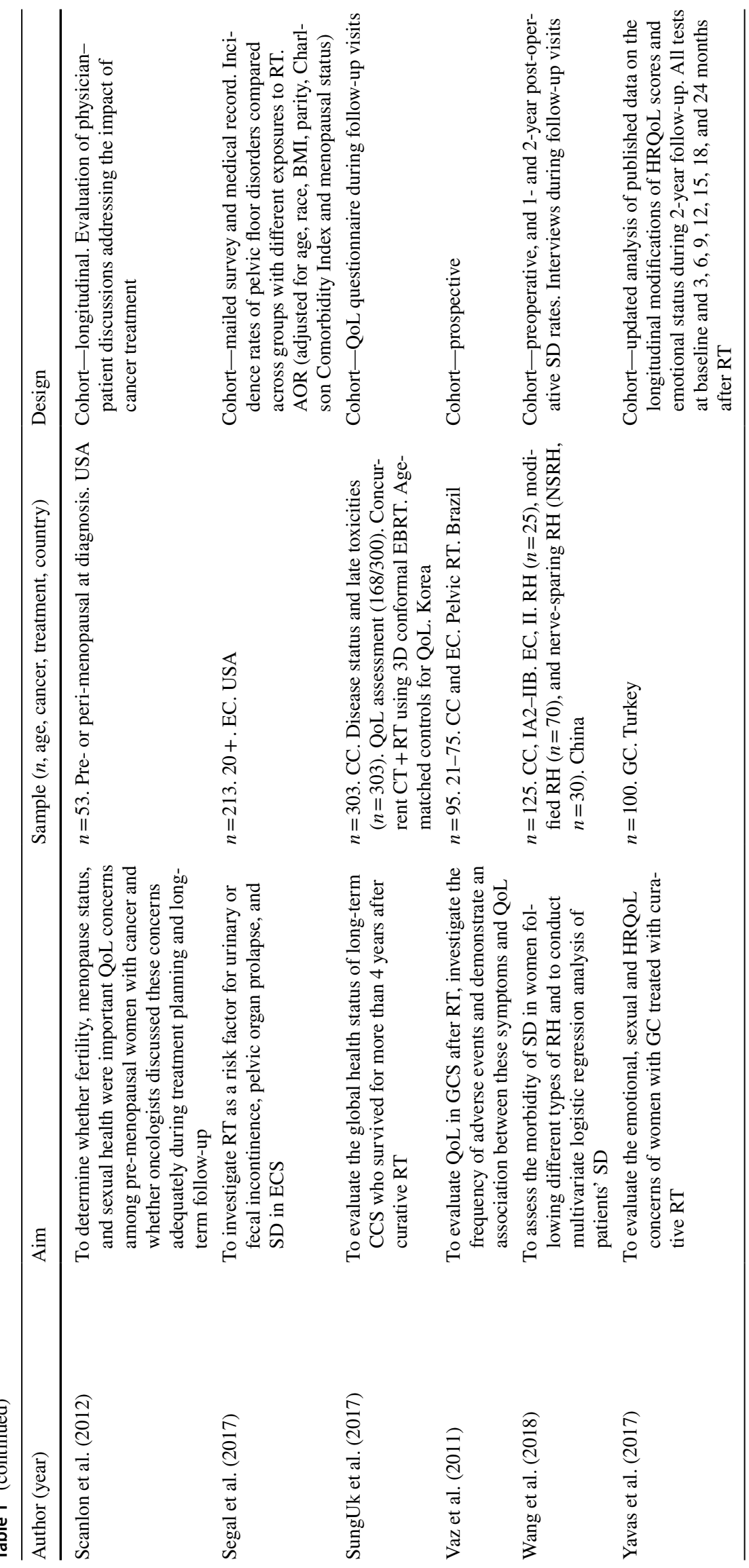


Table 2 Key risk factors of SQoL

\begin{tabular}{|c|c|c|c|}
\hline Risk factor & Association with SQoL & Studies* & Cancer type \\
\hline \multirow[t]{3}{*}{ 1.1 Age and menopausal status } & $\begin{array}{l}\text { Older age }(<55) \text { : } \mathrm{SD} \text {, low sexual desire and shyness to } \\
\text { discuss sexual concerns }\end{array}$ & $10,17,24,25,37,42,45$ & $\mathrm{CC}, \mathrm{EC}, \mathrm{GC}, \mathrm{VC}$ \\
\hline & $\begin{array}{l}\text { Young age: worst SQoL outcomes and higher rehabili- } \\
\text { tation needs }\end{array}$ & $4,5,7,11,31,37$ & $\mathrm{CC}, \mathrm{EC}, \mathrm{VC}, \mathrm{GC}, \mathrm{OC}$ \\
\hline & $\begin{array}{l}\text { Menopause: long-term factor in QoL and SR. Premeno- } \\
\text { pausal women at diagnosis reported feeling the loss of } \\
\text { feminity }\end{array}$ & $11,32,39$ & $\mathrm{CC}, \mathrm{EC}, \mathrm{OC}$ \\
\hline 1.2 Relationship status & Single status: IBI, SD and higher rehabilitation needs & $3,5,6,17,25,28,32,46$ & $\mathrm{CC}, \mathrm{EC}, \mathrm{GC}, \mathrm{VC}$ \\
\hline \multirow[t]{6}{*}{ 1.3 Treatment modality } & $\begin{array}{l}\text { Pelvic radiotherapy (RT): severe SD and VD, sub- } \\
\text { stantial late toxicity, psychosexual and psychosocial } \\
\text { distress and impaired QoL. Risk factor in menopause, } \\
\text { lymphedema and rehabilitation needs }\end{array}$ & $\begin{array}{l}2,5,19,23,29,30,33 \\
\quad 40,42,44,45,46\end{array}$ & $\mathrm{CC}, \mathrm{EC}, \mathrm{VC}, \mathrm{VAC}(1), \mathrm{GC}$ \\
\hline & Chemotherapy (CT): altered SR and IBI & 11,46 & GC \\
\hline & $\begin{array}{l}\text { RT + CT: }(\text { above })+\text { FIC, changes in hormones, marital } \\
\text { cohesion and social role functions }\end{array}$ & $1,39,43$ & $\mathrm{CC}, \mathrm{EC}$ \\
\hline & $\begin{array}{l}\text { Radical hysterectomy (RH) removal of the reproduc- } \\
\text { tive organs affects SR. SD, VD, numbness (labia), } \\
\text { lymphedema, depression, anxiety and emotional } \\
\text { distress }\end{array}$ & $11,27,38,39,40,45$ & $\mathrm{CC}, \mathrm{EC}, \mathrm{OC}$ \\
\hline & $\begin{array}{l}\text { Radical vaginal trachelectomy, radical vulvar excisions } \\
\text { or ovaries removal: pain, bleeding, SD, feelings of } \\
\text { isolation, IBI, FIC, lymphedema, and menopause }\end{array}$ & $6,3,34,11,40,45$ & $\mathrm{CC}, \mathrm{VC}, \mathrm{EC}, \mathrm{OC}$ \\
\hline & $\begin{array}{l}\text { Pelvic surgeries or GC treatment (unspecified) SD and } \\
\text { VD, lower sexual and relationship satisfaction, pain } \\
\text { and bleeding, menopause, changed sexual self-con- } \\
\text { cept, FIC, lower QoL }\end{array}$ & $3,7,10,11,21,24,36$ & $\mathrm{CC}, \mathrm{EC}, \mathrm{GC}, \mathrm{OC}$ \\
\hline
\end{tabular}

SD—sexual dysfunction, VD—vaginal dysfunction, SR—sexual response, IBI—impaired body image, CC—cervical cancer, EC—endometrial cancer, GC - gynaecological cancer, OC - ovarian cancer, VC—vulvar cancer, VAC—vaginal cancer FIC—feminine identity crisis/grief of womanhood $*$ Study numbers refer to the first column of Table 1 (Appendix A)

[29] and Wang et al. [33] have established older age as a predictor of decreased sexual function. Despite this, premenopausal GCS may be particularly at risk of feeling the loss of feminity or developing a fear their partner might leave them $[14,30,35]$. Menopausal status can also be altered by cancer treatment and affect sexual response [35].

\section{Relationship status}

Nine studies established a link between relationship status and SQoL [28, 30, 32, 34, 36, 37, 40-42]. Single women (i.e., unmarried, not in a stable relationship or not living with a significant other) may feel more vulnerable in new relationships [41], be at risk of an impaired body image [28], and have higher rehabilitation needs [34]. According to Barlow et al. [40], intimacy and relationship status are more closely linked to sexual satisfaction than physical arousal. Not surprisingly, relationship status was associated with sexual activity [28, 42] and it is also a predictor of sexual function and sexual interest [32, 37]. Finally, Pinar et al. [30] found that couples in an arranged marriage or those married for more than 30 years suffer from lower sexual interest and sexual dysfunction.

\section{Treatment modality}

The impact of cancer treatment on SQoL is significant, with 25 studies reporting an association with SQoL. As such, Table 2 shows common complaints among GCS after radiotherapy, chemotherapy, and surgery. For example, pelvic radiation may alter vaginal conditions and cause frequent and intense dyspareunia, which in turn can lead to a fear of sexual contact and impact all aspects of sexual response (desire, arousal, orgasm, and resolution), sexual activity, and sexual satisfaction [28, 29, 43-49].

Surgeries to the reproductive organs, such as radical hysterectomy, can not only affect sexual response, but also lead to psychosocial distress due to feelings of grief (e.g., loss of womanhood) or issues with marital cohesion [33, $35,48,50]$. Furthermore, certain treatments can induce conditions such as lymphedema or menopause, which can impact on sexual desire, sexual intercourse, and overall QoL [34, 35, 48, 48]. Finally, health professionals should be aware that treatment affect women differently. In a study from Stead et al. [35], most women did not have sex during chemotherapy, while others felt it helped them maintain a sense of normality, protect their feminine identity, 
cope with treatment, boost confidence, and feel sexually desirable.

\section{Protective factors of SQoL}

In line with the Salutogenic Theory [19], this review identified the need for a holistic, patient-centric and multidisciplinary approach to SQoL. This section covers the protective factors of SQoL (Table 3) and the role of the healthcare system, policy makers, and partners of GCS in preventing and reducing the negative consequences of gynaecological cancers.

\section{Clinician's knowledge and confidence}

Eleven studies recommended that health professionals should build knowledge and confidence required to address SQoL. First, seven studies [29, 34, 42, 46, 49, 52, 53] revealed the importance of developing an awareness of the risk factors and adverse effects of diagnosis and treatment on SQoL. In fact, Vaz et al. [49] suggested that knowledge of the frequency, duration, and interference of the adverse effects of radiotherapy may facilitate early intervention and reduce the burden of treatment sequelae. Second, four studies [54-57] emphasised the need to provide training and support to grow confidence and communication skills among nurses and clinicians. Furthermore, Molassiotis et al. [52] encouraged healthcare providers to develop an awareness of cultural views of health and sexuality to support the delivery of culturally sensitive care.

\section{Preventive medical approach}

Traditionally, the emphasis of gynaecological cancer treatment has been on improving survival rates. Besides adding years to life, there is now a growing appreciation for the need to improve the quality of those years. As such, four studies $[29,42,51,58]$ reported on preventive measures that address the modifiable risk factors for pelvic floor disorders, menopause, and lymphedema. For instance, identifying patients at high risk of lower lymph lymphedema may help avoid unnecessary lymphadenectomy and bilateral adnexectomy [42, 42]. Procedures such as nerve-sparing surgery, ovary preservation, or the extension of the vagina may also help lessen the negative effects of treatment, although more research is needed [33].

\section{Risk and needs assessment}

Twelve studies $[14,31,34,42,46,49-51,54,57,59,60]$ supported interdisciplinary efforts in the assessment of risks and early identification of needs for SQoL. Findings from McCallum et al. [14] indicated that understanding patients' long-term needs, desire for help, and barriers to access can help health professionals support GGS in achieving a healthy sexuality. Finally, Juraskova et al. [57] concluded that the quality of sexual relations is the best predictor of sexual function, and sexual function is the best predictor of QoL. As quality seems to prevail over quantity, understanding the perceived quality of sexual relations indicators from a patient's perspective is crucial to needs assessment $[55,57$, $59,61]$.

Table 3 Key protective factors of SQoL

\begin{tabular}{|c|c|c|c|}
\hline Protective factors & Who is involved & Classification* & Studies** \\
\hline 2.1. Clinicians' knowledge and confidence & $\begin{array}{l}\text { Health practitioners } \\
\text { Policy makers }\end{array}$ & Reinforcing & $5,8,14,15,29,30,32,35,41,42,44$ \\
\hline 2.2. Preventive medical approach & Gynaecologist-oncologists & Reinforcing & $32,39,42,43$ \\
\hline 2.3. Risk and needs assessment & $\begin{array}{l}\text { Health practitioners } \\
\text { Policy makers }\end{array}$ & Reinforcing & $5,7,14,21,24,27,30,32,33,35,39,44$ \\
\hline 2.4. Patient-clinician communication & $\begin{array}{l}\text { Health practitioners } \\
\text { GCS (and partners) }\end{array}$ & Reinforcing & $3,10,14,21,27,33,35$ \\
\hline 2.5. Relationship quality & $\begin{array}{l}\text { Health practitioners } \\
\text { GCS and partners }\end{array}$ & Reinforcing & $1,3,7,8,9,11,12,17,21,23,29,33,34$ \\
\hline 2.6. Psychosocial support & $\begin{array}{l}\text { Health practitioners } \\
\text { GCS and supporters }\end{array}$ & Reinforcing & $4,6,7,11,13,15,18,32,39$ \\
\hline 2.7. Symptom management & $\begin{array}{l}\text { Health practitioners } \\
\text { GCS (and partners) }\end{array}$ & Enabling & $2,7,20,22,29,30,3233,34,44,45$ \\
\hline 2.8. Accessibility of psychosexual care & $\begin{array}{l}\text { Health practitioners } \\
\text { Policy makers }\end{array}$ & Enabling & $\begin{array}{l}3,5,6,7,8,10,12,13,14,15,18,20,22 \\
\quad 28,29,31,34,41\end{array}$ \\
\hline 2.9. Self-efficacy in the rediscovery of sexuality & $\begin{array}{l}\text { GCS (and partners) } \\
\text { Health practitioners }\end{array}$ & Predisposing & $7,8,9,11,12,16,20,22,23,29,32,34,45$ \\
\hline
\end{tabular}

*Classification of factors refers to PRECEDE-PROCEED [26]

**Study numbers refer to the first column of Table 1 (Appendix A) 


\section{Patient-clinician communication}

Seven studies [30, 40, 47, 50, 54, 57, 59] supported the positive effect of ongoing communication on the impact of diagnosis and treatment on SQoL. Furthermore, three studies $[14,52,59]$ recommended giving written information for women embarrassed to raise sexual concerns. This recommendation strengthens the case for communication training to help remove clinicians' barriers and ensure women's concerns are addressed [54-57]. To this effect, Jensen et al. [47] suggested the PLISSIT model (Permission, Limited Information, Specific Suggestion, Intensive Therapy) as a useful guide to initiate the patient-clinician dialogue.

\section{Relationship quality}

Thirteen studies [14, 35, 36, 40, 45, 47, 52, 56, 59, 61-64] stated the partner's role in SQoL and the importance of the quality of the partner's relationship. According to Carta et al. [45] and Barlow et al. [40], relational and psychological factors may have a greater impact on sexuality than the physical side effects of cancer treatment. In fact, women who are in a committed and supportive relationship, and create emotional intimacy with their partner, may find it easier to resume and maintain a satisfying sexual relationship [40, 45, 55, 65]. Health practitioners can create a supportive environment for couples by involving partners in care planning and taking their emotional needs and perspectives into account $[52,56$, $59,61]$.

\section{Psychosocial support}

Nine studies [14, 27, 35, 41, 42, 51, 55, 66, 67] highlighted the role of psychosocial support in SQoL. YGCS may benefit from peer-to-peer support, such as moderated web-based support groups with other GCS, to share experiences, provide mutual validation and support, and break feelings of isolation and aloneness [27, 41, 66, 67]. Psychosocial support may also help YGCS cope with psychosexual distress, anxiety, body image struggles, and infertility-related distress and, therefore, enhancing emotional wellbeing and QoL [14, $66,51]$.

\section{Symptom management}

Eleven studies [14, 33, 42, 43, 46, 47, 49, 56, 64, 68, 69] examined the accessibility of patient-centric support for pain and symptom management. According to McCallum et al. [14], many GCS said they would have a healthy sexual life if they could manage the pain and symptoms post-treatment. Moreover, Ferrandina et al. [42] and Jones et al. [64] proposed referrals to specialist clinics dedicated to lymphedema and sexual health to improve SQoL. Finally, four studies $[43,56,47,33]$ covered the role of lubricant and regular, long-term vaginal dilation in sexual recovery. Evidence suggested that interventions aimed at improving both nurses' and patients' self-efficacy in vaginal dilation may improve compliance $[43,56,47]$.

\section{Accessibility of psychosexual care}

The most recurrent theme was the delivery of multidisciplinary psychosexual care, as reported in 18 studies [14, 30, 32, 34 , 38, 40, 41, 52-56, 61, 64, 66-69]. Furthermore, offering counselling and psychosexual support may help couples develop communication skills, renegotiate sexual practices or adopt non-genital intimacy [35, 47, 52, 59, 61-63, 68]. Finally, web-based [61, 66, 67], home-based [69, 32], and nurse-led interventions $[68,56]$ may help enhance service accessibility.

\section{Self-efficacy in the rediscovery of sexuality}

Healthy sexuality concepts such as body image (how a woman feels about her body) and sexual self-schema (how a woman sees herself sexually) may be affected throughout the cancer journey [14, 30, 70]. As such, 13 studies [14, 33, $35,42,45,52,56,61,63,64,68,69,71]$ recommended supporting GCS in the rediscovery of their sexuality. The focus should be on improving communication and self-efficacy through public awareness, information, education and access to support services to help GCS maintain a sense of normality and control over their lives [41, 63, 35, 14, 42]. Moreover, addressing misconceptions and taboos about sexuality may encourage GCS to seek help in the rediscovery of their sexuality [61, 47, 30, 45, 33]. Finally, Brotto et al. [71] demonstrated that mindfulness-based interventions can improve sexual response and reduce psychosexual distress.

\section{Discussion}

This systematic review included 46 studies that examined the association between factors of SQoL and gynaecological cancers. Our findings suggested that SQoL varies across subgroups based on age, menopausal status, relationship status, and treatment modality. Key protective factors included clinicians' knowledge and confidence, preventive medical approach, risk and needs assessment, patient-clinician communication, relationship quality, psychosocial support, symptom management, accessibility of psychosexual care, and self-efficacy in the rediscovery of sexuality.

The included studies provided an understanding of how the major causes of SQoL can help clinicians and policy makers target at-risk individuals through risk reduction (risk 
factors) and prevention strategies (protective factors). The findings indicated that a holistic, patient-centric and multidisciplinary approach to SQoL is supportive of SQoL among GCS. Subsequently, the first step in addressing SQoL is for all health professionals involved in patients' care to understand who is most at risk of an impaired SQoL and how different treatment modalities may impact on SQoL based on patients' personal characteristics or circumstances. To this effect, William et al. [54] recommended establishing clear practice guidelines, promote shared responsibility and offer training to medical staff for the integration of sexuality in standard care.

\section{Strengths and limitations}

The strengths of this review included the use of a systematic, blinded and peer-reviewed process to assess the selection and quality of individual studies. One limitation was that although a number of included studies discussed the impact of gynaecological cancer treatment, they did not provide specifics about the treatment modalities, which made it difficult to ascertain their relative impact on SQoL. Some studies also failed to account for potential confounders in the analysis that could have explained variations in SQoL. Finally, another limiting factor in performing this review was the lack of a clear definition on SQoL for GCS. Although an extensive search strategy mitigated that risk, developing a clear working definition of SQoL for GCS would help inform future research and evidence-based practice.

\section{Conclusion}

When it comes to SQoL, a common mistake is to wait until the treatment has taken place to discuss sexual complaints. To reduce the burden of gynaecological cancers, this review identified the factors of SQoL to inform the steps health practitioners can take to support a proactive approach to SQoL. First, conduct risk and needs assessments while providing education to GCS and their partners on the impact of different treatment options on SQoL. This process should start in the initial consultations and include an exploration of preventative surgeries. Second, keep the patient-clinician dialogue open to evaluate treatment outcomes and sexual health needs during routine clinical assessments. Third, provide strategies to improve pain and symptom management or referrals to specialist clinics. Finally, consider the needs of partnered and single women in the provision of psychosexual care and psychosocial support.

Finally, our findings indicated that young single women who were premenopausal at diagnosis and underwent radiotherapy or radical surgeries of the reproductive system have an increased risk for severe sexual dysfunction and psychosexual distress. Although the evidence suggests that YGGS want help in dealing with psychosexual distress, more research is needed to inform intervention design. Consequently, the authors of this study are currently undertaking a qualitative study to explore the strategies that are acceptable in protecting and improving SQoL among YGCS.

\section{Appendix A}

\section{See Table 1.}

Author contributions MR, JL, AH, and LM: project development, data screening, and manuscript review. MR: data collection, extraction and analysis, quality assessment, and manuscript writing.

Funding This research did not receive any specific grant from funding agencies in the public, commercial, or not-for-profit sectors.

\section{Declarations}

Conflict of interest The authors declare no potential conflicts of interest.

Ethics approval This article contains already published data.

Consent to participate No informed consent was needed, as all the studies included in this review are already published.

Consent for publication The authors consent to publication.

Open Access This article is licensed under a Creative Commons Attribution 4.0 International License, which permits use, sharing, adaptation, distribution and reproduction in any medium or format, as long as you give appropriate credit to the original author(s) and the source, provide a link to the Creative Commons licence, and indicate if changes were made. The images or other third party material in this article are included in the article's Creative Commons licence, unless indicated otherwise in a credit line to the material. If material is not included in the article's Creative Commons licence and your intended use is not permitted by statutory regulation or exceeds the permitted use, you will need to obtain permission directly from the copyright holder. To view a copy of this licence, visit http://creativecommons.org/licenses/by/4.0/.

\section{References}

1. Wang J-W, Sun L, Li J, Cong X-H, Chen X-F, Tang Z, Yu D-H, Zhang T-R, Luo Z-N, Yuan Z-P (2015) Comorbid chronic diseases and their associations with quality of life among gynecological cancer survivors. BMC Public Health 15(1):965. https://doi.org/ 10.1186/s12889-015-2240-1

2. Carr SV (2015) Psychosexual health in gynecological cancer. Int J Gynecol Obstet 131:S159-S163. https://doi.org/10.1016/j.ijgo. 2015.06.014

3. Akalin A, Pinar G (2016) Unmet needs of women diagnosed with gynecologic cancer: an overview of literature. Palliat Care Med $6(2): 1-6$ 
4. Arrington R, Cofrancesco J, Wu AW (2004) Questionnaires to measure sexual quality of life. Qual Life Res 13(10):1643-1658. https://doi.org/10.1007/s11136-004-7625-Z

5. Zeng YC, Liu X, Loke AY (2012) Addressing sexuality issues of women with gynaecological cancer: Chinese nurses' attitudes and practice. J Adv Nurs 68(2):280-292. https://doi.org/10.1111/j. 1365-2648.2011.05732.x

6. World Health Organization (2018) Defining sexual health. http:// www.who.int/reproductivehealth/topics/sexual_health/sh_defin itions/en.

7. Dizon DS, Suzin D, McIlvenna S (2014) Sexual health as a survivorship issue for female cancer survivors. Oncologist 19(2):202. https://doi.org/10.1634/theoncologist.2013-0302

8. Carpenter KM, Andersen BL, Fowler JM, Maxwell GL (2009) Sexual self schema as a moderator of sexual and psychological outcomes for gynecologic cancer survivors. Arch Sex Behav 38(5):828-841. https://doi.org/10.1007/s10508-008-9349-6

9. L. Dove MWW, Natalie, (2000) Cognitive distraction and women's sexual functioning. J Sex Marital Ther 26(1):67-78. https:// doi.org/10.1080/009262300278650

10. Wiederman MW (2000) Women's body image self-consciousness during physical intimacy with a partner. J Sex Res 37(1):60-68. https://doi.org/10.1080/00224490009552021

11. Beckjord E, Compas BE (2007) Sexual quality of life in women with newly diagnosed breast cancer. J Psychosoc Oncol 25(2):1936. https://doi.org/10.1300/J077v25n02_02

12. Zeng YC, Li Q, Li X, Loke AY (2012) Chinese women's sexuality concerns after gynecologic cancer. Cancer Nurs 35(4):257-264. https://doi.org/10.1097/NCC.0b013e31822f65e9

13. Audette C, Waterman J (2010) The sexual health of women after gynecologic malignancy. J Midwife Womens Health 55(4):357362. https://doi.org/10.1016/j.jmwh.2009.10.016

14. McCallum M, Lefebvre M, Jolicoeur L, Maheu C, Lebel S (2012) Sexual health and gynecological cancer: conceptualizing patient needs and overcoming barriers to seeking and accessing services. J Psychosom Obstet Gynecol 33(3):135-142. https://doi.org/10. 3109/0167482X.2012.709291

15. Rannestad T (2010) Factors related to quality of life in longterm survivors of gynecological cancer. Exp Rev Obst Gynecol 5(1):105-113. https://doi.org/10.1586/eog.09.61

16. Beesley V, Eakin E, Steginga S, Aitken J, Dunn J, Battistutta D (2008) Unmet needs of gynaecological cancer survivors: implications for developing community support services. Psycho-Oncol J Psychol Soc Behav Dimens Cancer 17(4):392-400. https://doi. org/10.1002/pon.1249

17. Basson R (2001) Female sexual response: the role of drugs in the management of sexual dysfunction. Obstet Gynecol 98(2):350 353. https://doi.org/10.1016/S0029-7844(01)01452-1

18. Wilmoth MC, Hatmaker-Flanigan E, LaLoggia V, Nixon T Ovarian cancer survivors: qualitative analysis of the symptom of sexuality. In: Oncology nursing forum, 2011. vol 6. doi:https://doi.org/ 10.1188/11.ONF.699-708

19. Antonovsky A (1996) The salutogenic model as a theory to guide health promotion. Health Promot Int 11(1):11-18

20. Moher D, Liberati A, Tetzlaff J, Altman DG, Group P (2009) Preferred reporting items for systematic reviews and meta-analyses: the PRISMA statement. PLoS Med 6(7):e1000097. https://doi. org/10.1371/journal.pmed.1000097

21. Shamseer L, Moher D, Clarke M, Ghersi D, Liberati A, Petticrew M, Shekelle P, Stewart LA (2015) Preferred reporting items for systematic review and meta-analysis protocols (PRISMA-P) 2015: elaboration and explanation. BMJ. https://doi.org/10.1136/bmj. g7647

22. Royal College of Obstetricians \& Gynaecologists (2018) Gyneacological cancers. http://www.rcog.org.uk/en/patients/menopause/ gynaecological-cancers. Accessed 17 January 2018
23. Cancer Research UK (2017) Women's cancers (gynaecological cancer). http://www.cancerresearchuk.org/about-cancer/womens-cancer. Accessed 20 February 2018

24. Critical Appraisal Skills Programme UK. (n.d.) CASP checklists. https://casp-uk.net/casp-tools-checklists/.

25. William WN Jr, Heymach JV, Kim ES, Lippman SM (2009) Molecular targets for cancer chemoprevention. Nat Rev Drug Discov 8(3):213-225. https://doi.org/10.1038/nrd2663

26. Crosby R, Noar SM (2011) What is a planning model? An introduction to PRECEDE-PROCEED. J Public Health Dent 71:S7-S15

27. Jefferies $\mathrm{H}$, Clifford C (2011) Aloneness: the lived experience of women with cancer of the vulva. Eur J Cancer Care 20(6):738746. https://doi.org/10.1111/j.1365-2354.2011.01246.x

28. Yavas G, Yavas C, Dogan NU, Ilhan TT, Dogan S, Karabagli P, Ata O, Yuce E, Celik C (2017) Pelvic radiotherapy does not deteriorate the quality of life of women with gynecologic cancers in long-term follow-up: a 2 years prospective singlecenter study. J Cancer Res Ther 13(3):524-532. https://doi.org/ 10.4103/0973-1482.187243

29. Segal S, John G, Sammel M, Andy UU, Chu C, Arya LA, Brown J, Schmitz K (2017) Urinary incontinence and other pelvic floor disorders after radiation therapy in endometrial cancer survivors. Maturitas 105:83-88. https://doi.org/10.1016/j.maturitas. 2017.03.313

30. Pinar G, Kaplan S, Akalin A, Abay H, Ayhan A, Ayhan Y (2016) Evaluation of sexual dysfunction and affecting factors in Turkish women with gynecological cancer. Sex Disabil 34(1):49-62. https://doi.org/10.1007/s11195-015-9411-y

31. Corrêa C, Leite I, Andrade A, Souza Sérgio Ferreira A, Carvalho S, Guerra M, Corrêa CSL, Leite ICG, Andrade APS, de Souza Sérgio Ferreira A, Carvalho SM, Guerra MR, (2016) Sexual function of women surviving cervical cancer. Arch Gynecol Obstet 293(5):1053-1063. https://doi.org/10.1007/ s00404-015-3857-0

32. Armbruster SD, Song J, Bradford A, Carmack CL, Lu KH, BasenEngquist KM (2016) Sexual health of endometrial cancer survivors before and after a physical activity intervention: a retrospective cohort analysis. Gynecol Oncol 143(3):589-595. https://doi. org/10.1016/j.ygyno.2016.09.016

33. Wang XQ, Chen CL, Liu P, Li WL, Wang LL, Liu YL (2018) The morbidity of sexual dysfunction of 125 Chinese women following different types of radical hysterectomy for gynaecological malignancies. Arch Gynecol Obstet 297(2):459-466. https://doi. org/10.1007/s00404-017-4625-0

34. Jeppesen MM, Mogensen O, Dehn P, Jensen PT (2015) Needs and priorities of women with endometrial and cervical cancer. J Psychosom Obstet Gynecol 36(3):122-132. https://doi.org/10. 3109/0167482x.2015.1059417

35. Stead ML, Fallowfield L, Selby P, Brown JM (2007) Psychosexual function and impact of gynaecological cancer. Best Pract Res Clin Obstet Gynaecol 21(2):309-320. https://doi.org/10.1016/j.bpobg yn.2006.11.008

36. Carter J, Huang H, Chase DM, Walker JL, Cella D, Wenzel L (2012) Sexual function of patients with endometrial cancer enrolled in the gynecologic oncology group LAP2 study. Int J Gynecol Cancer 22(9):1624-1633. https://doi.org/10.1097/IGC. 0b013e31827277fa

37. De Melo Ferreira AP, De Figueiredo EM, Lima RA, Cândido EB, De Castro Monteiro MV, De Figueiredo Franco TMR, Traiman P, Da Silva-Filho AL (2012) Quality of life in women with vulvar cancer submitted to surgical treatment: a comparative study. Eur J Obstet Gynecol Reprod Biol 165(1):91-95. https://doi.org/10. 1016/j.ejogrb.2012.06.027

38. Bretschneider CE, Bensen JT, Geller EJ, Gehrig PA, Wu JM, Doll KM (2017) Perioperative sexual interest in women with suspected 
gynecologic malignancies 146(1):109-113. https://doi.org/10. 1016/j.ygyno.2017.04.001

39. Komblith AB, Powell M, Regan MM, Bennett S, Krasner C, Moy B, Younger J, Goodman A, Berkowitz R, Winer E (2007) Longterm psychosocial adjustment of older vs younger survivors of breast and endometrial cancer. Psychooncology 16(10):895-903. https://doi.org/10.1002/pon.1146

40. Barlow EL, Hacker NF, Hussain R, Parmenter G (2014) Sexuality and body image following treatment for early-stage vulvar cancer: a qualitative study. J Adv Nurs 70(8):1856-1866. https://doi.org/ 10.1111/jan.12346

41. Lloyd PA, Briggs EV, Kane N, Jeyarajah AR, Shepherd JH (2014) Women's experiences after a radical vaginal trachelectomy for early stage cervical cancer. A descriptive phenomenological study. Eur J Oncol Nurs 18 (4):362-371. doi:https://doi.org/10.1016/j. ejon.2014.03.014

42. Ferrandina G, Petrillo M, Mantegna G, Fuoco G, Terzano S, Venditti L, Marcellusi A, De Vincenzo R, Scambia G (2014) Evaluation of quality of life and emotional distress in endometrial cancer patients: a 2-year prospective, longitudinal study. Gynecol Oncol 133(3):518-525. https://doi.org/10.1016/j.ygyno.2014.03.015

43. Bakker RM, Vermeer WM, Creutzberg CL, Mens JWM, Nout RA, ter Kuile MM (2015) Qualitative accounts of patients' determinants of vaginal dilator use after pelvic radiotherapy. J Sex Med 12(3):764-773. https://doi.org/10.1111/jsm.12776

44. Hofsjö A, Bergmark K, Blomgren B, Jahren H, Bohm-Starke N (2018) Radiotherapy for cervical cancer-impact on the vaginal epithelium and sexual function. Acta Oncol 57(3):338-345. https://doi.org/10.1080/0284186X.2017.1400684

45. Carta G, D’Alfonso A, Di Nicola M, Di Nicola L, Mastrocola N, Carta A, Necozione S, Di Cesare E, Patacchiola F (2014) Impact of surgery and radiotherapy in women with uterine malignancies. Eur J Gynaecol Oncol 35(6):662-665

46. Barraclough LH, Routledge JA, Farnell DJJ, Burns MP, Swindell R, Livsey JE, Davidson SE (2012) Prospective analysis of patientreported late toxicity following pelvic radiotherapy for gynaecological cancer. Radiother Oncol 103(3):327-332. https://doi.org/ 10.1016/j.radonc.2012.04.018

47. Jensen PT, Groenvold M, Klee MC, Thranov I, Petersen MA, Machin D (2003) Longitudinal study of sexual function and vaginal changes after radiotherapy for cervical cancer. Int J Radiat Oncol Biol Phys 56(4):937-949. https://doi.org/10.1016/s03603016(03)00362-6

48. Pieterse QD, Maas CP, ter Kuile MM, Lowik M, van Eijkeren MA, Trimbos J, Kenter GG (2006) An observational longitudinal study to evaluate miction, defecation, and sexual function after radical hysterectomy with pelvic lymphadenectomy for early-stage cervical cancer. Int J Gynecol Cancer 16(3):1119-1129. https://doi.org/ 10.1111/j.1525-1438.2006.00461.x

49. Vaz AF, Conde DM, Costa-Paiva L, Morais SS, Esteves SB, Pinto-Neto AM (2011) Quality of life and adverse events after radiotherapy in gynecologic cancer survivors: a cohort study. Arch Gynecol Obstet 284(6):1523-1531. https://doi.org/10.1007/ s00404-011-1886-X

50. Aerts L, Enzlin P, Verhaeghe J, Poppe W, Vergote I, Amant F (2015) Sexual functioning in women after surgical treatment for endometrial cancer: A prospective controlled study. J Sex Med 12(1):198-209. https://doi.org/10.1111/jsm.12764

51. Mantegna G, Petrillo M, Fuoco G, Venditti L, Terzano S, Anchora LP, Scambia G, Ferrandina G (2013) Long-term prospective longitudinal evaluation of emotional distress and quality of life in cervical cancer patients who remained disease-free 2-years from diagnosis. BMC Cancer 13:127. https://doi.org/10.1186/ 1471-2407-13-127

52. Molassiotis A, Chan CWH, Yam BMC, Chan ESJ, Lam CSW (2002) Life after cancer: Adaptation issues faced by Chinese gynaecological cancer survivors in Hong Kong. Psychooncology 11(2):114-123. https://doi.org/10.1002/pon.540

53. Scanlon M, Blaes A, Geller M, Majhail NS, Lindgren B, Haddad T (2012) Patient satisfaction with physician discussions of treatment impact on fertility, menopause and sexual health among pre-menopausal women with cancer. J Cancer 3:217-225. https://doi.org/10.7150/jca.4408

54. Williams NF, Hauck YL, Bosco AM (2017) Nurses' perceptions of providing psychosexual care for women experiencing gynaecological cancer. Eur J Oncol Nurs 30:35-42. https://doi. org/10.1016/j.ejon.2017.07.006

55. Zeng YC, Li DM, Loke AY (2011) Life after cervical cancer: quality of life among Chinese women. Nurs Health Sci 13(3):296-302. https://doi.org/10.1111/j.1442-2018.2011. 00616.x

56. Bakker RM, Mens JWM, de Groot HE, Tuijnman-Raasveld CC, Braat C, Hompus WCP, Poelman JGM, Laman MS, Velema LA, de Kroon CD, van Doorn HC, Creutzberg CL, ter Kuile MM (2017) A nurse-led sexual rehabilitation intervention after radiotherapy for gynecological cancer. Support Care Cancer 25(3):729737. https://doi.org/10.1007/s00520-016-3453-2

57. Juraskova I, Bonner C, Bell ML, Sharpe L, Robertson R, Butow P (2012) Quantity vs. quality: an exploration of the predictors of posttreatment sexual adjustment for women affected by early stage cervical and endometrial cancer. J Sex Med 9(11):2952-2960. doi:https://doi.org/10.1111/j.1743-6109.2012.02860.x

58. Sung Uk L, Young Ae K, Young-Ho Y, Yeon-Joo K, Myong Cheol L, Sang-Yoon P, Sang-Soo S, Ji Eun P, Joo-Young K (2017) General health status of long-term cervical cancer survivors after radiotherapy. Strahlenther Onkol 193(7):543-551. https://doi. org/10.1007/s00066-017-1143-8

59. Aerts L, Enzlin P, Verhaeghe J, Vergote I, Amant F (2009) Sexual and psychological functioning in women after pelvic surgery for gynaecological cancer. Eur J Gynaecol Oncol 30(6):652-656

60. Jensen PT (2007) Gynaecological cancer and sexual functioning: Does treatment modality have an impact? Sexologies 16(4):279285. https://doi.org/10.1016/j.sexol.2007.06.010

61. Vermeer WM, Bakker RM, Kenter GG, Stiggelbout AM, ter Kuile MM (2016) Cervical cancer survivors' and partners' experiences with sexual dysfunction and psychosexual support. Support Care Cancer 24(4):1679-1687. https://doi.org/10.1007/ s00520-015-2925-0

62. Afiyanti Y, Milanti A (2013) Physical sexual and intimate relationship concerns among Indonesian cervical cancer survivors: A phenomenological study. Nurs Health Sci 15(2):151-156. https:// doi.org/10.1111/nhs.12006

63. Perz J, Ussher JM, Gilbert E (2013) Constructions of sex and intimacy after cancer: $\mathrm{Q}$ methodology study of people with cancer, their partners, and health professionals. BMC Cancer. https://doi. org/10.1186/1471-2407-13-270

64. Jones GL, Jacques RM, Thompson J, Wood HJ, Hughes J, Ledger W, Mi A, Radley SC, Tidy JA (2016) The impact of surgery for vulval cancer upon health-related quality of life and pelvic floor outcomes during the first year of treatment: a longitudinal, mixed methods study. Psychooncology 25(6):656-662. https://doi.org/ 10.1002/pon.3992

65. Manne S, Badr H (2008) Intimacy and relationship processes in couples' psychosocial adaptation to cancer. Cancer 112(S11):2541-2555. https://doi.org/10.1002/cncr.23450

66. Wiljer D, Urowitz S, Barbera L, Chivers ML, Quartey NK, Ferguson SE, To M, Classen CC (2011) A qualitative study of an internet-based support group for women with sexual distress due to gynecologic cancer. J Cancer Educ 26(3):451-458. https://doi. org/10.1007/s13187-011-0215-1

67. Classen CC, Chivers ML, Urowitz S, Barbera L, Wiljer D, O’Rinn S, Ferguson SE (2013) Psychosexual distress in women with 
gynecologic cancer: a feasibility study of an online support group. Psychooncology 22(4):930-935. https://doi.org/10.1002/pon.3058

68. Li J, Huang J, Zhang J, Li Y (2016) A home-based, nurse-led health program for postoperative patients with early-stage cervical cancer: A randomized controlled trial. Eur J Oncol Nurs 21:174-180. https://doi.org/10.1016/j.ejon.2015.09.009

69. Aktaş D, Terzioğlu F (2015) Effect of Home Care Service on the Sexual Satisfaction of Patients with Gynecologic Cancer. Sex Disabil 33(2):243-252. https://doi.org/10.1007/s11195-014-9370-8

70. Carter J, Penson R, Barakat R, Wenzel L (2012) Contemporary quality of life issues affecting gynecologic cancer survivors. Hematol Oncol Clin North Am 26(1):169-194. https://doi.org/ 10.1016/j.hoc.2011.11.001
71. Brotto LA, Erskine Y, Carey M, Ehlen T, Finlayson S, Heywood M, Kwon J, McAlpine J, Stuart G, Thomson S, Miller D (2012) A brief mindfulness-based cognitive behavioral intervention improves sexual functioning versus wait-list control in women treated for gynecologic cancer. Gynecol Oncol 125(2):320-325. https://doi.org/10.1016/j.ygyno.2012.01.035

Publisher's Note Springer Nature remains neutral with regard to jurisdictional claims in published maps and institutional affiliations. 